\title{
Increased glomerulonephritis recurrence after living related donation
}

\author{
A. L. Kennard ${ }^{1 \dagger}$, S. H. Jiang ${ }^{1,2+}$ and G. D. Walters ${ }^{1,2,3,4^{*}}$
}

\begin{abstract}
Background: Kidney transplantation confers superior outcomes for patients with end stage kidney disease, and live donor kidneys associate with superior outcomes compared to deceased donor kidneys. Modern immunosuppression has improved rejection rates and transplant survival and, as a result, recurrence of glomerulonephritis has emerged as a major cause of allograft loss. However, many glomerulonephritides have significant genetic risk which may manifest through kidney intrinsic or systemic mechanisms. We hypothesise that heritable kidney intrinsic predisposition to glomerulonephritis will result in increased risk of glomerulonephritis recurrence in kidneys transplanted from genetically related donors.

Methods: We investigated the effect of living related donation on rates of recurrence and subsequent graft outcomes in 7236 patient from 28 years of ANZDATA transplant registry data. Data were analysed in R, using Kaplan Meier Survival analysis and adjusted analyses performed using Cox Proportional Hazards methods. A competing risk model was also analysed.

Results: Glomerulonephritis recurrence rates were significantly higher in living related donor grafts compared to either living unrelated or deceased donor grafts $(p<0$.001). In IgA nephropathy, transplantation from living related donor kidneys demonstrated a 10 year recurrence rate of $16 \cdot 7 \%$ compared to $7 \cdot 1 \%$ in living unrelated donors and $9 \cdot 2 \%$ in deceased donors (HR:1 $\cdot 7,95 \% \mathrm{Cl}: 1 \cdot 26-2 \cdot 26, p=0 \cdot 0005$ for living related vs deceased donors). In focal segmental glomerulosclerosis, risk of recurrence at 10 years was $14 \cdot 6 \%$ in living related donors compared to $10 \cdot 8 \%$ in living unrelated donors and $6 \cdot 6 \%$ in deceased donors (HR:2 $2,95 \% \mathrm{Cl} 1 \cdot 34-3 \cdot 64, p=0 \cdot 002)$ for living related vs deceased donors. Primary glomerulonephritis death censored graft survival was superior for living donor grafts, related or unrelated, compared to deceased donor grafts.
\end{abstract}

Conclusions: We identified a significant increase in the risk of glomerulonephritis recurrence in IgA Nephropathy and Focal Segmental Glomerulosclerosis in living related donors compared to a deceased donors.

Keywords: Kidney, Donor, Transplant, Survival, Glomerulonephritis, Recurrence

\section{Background}

Kidney transplantation confers the best prognosis [1] for patients with end stage renal failure and living kidney donation confers superior outcomes to deceased kidney donation [2]. However, modern immunosuppression has substantially improved rejection rates and as a result GN recurrence is increasingly a major cause of allograft loss

\footnotetext{
* Correspondence: giles.walters@act.gov.au

${ }^{\dagger}$ Equal contributors

'Department of Renal Medicine, The Canberra Hospital, PO Box 11, Woden, ACT 2605, Australia

2Department of Immunology and Infectious Diseases, John Curtin School of Medical Research, Australian National University, Canberra, Australia

Full list of author information is available at the end of the article
}

[3]. While conflicting reports suggested that recurrence of GN may $[4,5]$ or may not $[6,7]$ significantly reduce graft survival with post-transplant GN recurrence the third most common cause of allograft loss $[3,6,8]$.

It has been observed that kidneys transplanted from living donors have [9] both earlier onset [10-12] and increased rates $[4,5,7,13-17]$ of GN recurrence. Most glomerulonephritides have been associated with significant genetic risks $[9,10]$. It is unclear how this heritability contributes to disease pathogenesis, with both kidneyintrinsic [11] or systemic [12] mechanisms implicated. Equally, it is unclear whether the increased risk of GN recurrence is due to live donation per se or the presence 
of related donors in the donor population [18-21]. Furthermore, it is unclear what effect increased recurrence has on the superior outcomes typically associated with living related donation. In studies reporting increased risks of GN recurrence with living related donation, living related and unrelated graft survival was similar at 5 and 10 years $[14,22]$, whereas other studies report preserved survival advantage with living related donation regardless of GN recurrence [18, 23, 24].

We have investigated the effect of living related donation on rates of GN recurrence and subsequent graft outcomes from 28 years of ANZDATA transplant registry data, comparing living related, living unrelated and deceased donors.

\section{Methods}

\section{Study population}

The Australia and New Zealand Dialysis and Transplant Registry (ANZDATA) collects data on all renal transplants performed in Australia and New Zealand. Baseline clinical and demographic data are recorded with follow up data collected every 6 months from all transplant centres. Patient anonymity is assured with coding of data on entry. Recurrence of glomerulonephritis is recorded in the registry as the date of the relevant biopsy. Biopsy practice is defined by each centre according to its current clinical practice. This will necessarily have changed over the last 30 years with some centres moving to protocol biopsies. Biopsy indication is not available for this population currently. Data were extracted from ANZDATA for all renal allografts transplanted for patients with a primary GN between 1985 and 2013 within Australia and New Zealand. Transplants included first, second, or subsequent transplants. Primary end points were death censored graft loss (DCGS) or GN recurrence until December 2013.

\section{Statistical analyses}

All statistical analyses were carried out in R [13]. Baseline characteristics among groups were assessed using Pearson's chi-square test and one way ANOVA. In analyses of "Primary Glomerulonephritis" we included only patients with IgA Nephropathy (IGAN), Focal Segmental Glomerulosclerosis (FSGS), Membranous Nephropathy $(\mathrm{MN})$ and Mesangiocapillary Glomerulonephritis (MCGN), excluding those coded with "Other GN". Survival analyses were performed in R, using the $\operatorname{Surv}()$ function from the survival library [14] and the npsurv() and survplot() functions from the rms library [15]. Graphs are plotted with 95\% confidence intervals. Cox models were constructed to account for confounding due to differences across groups. Models adjusted for age, sex, dialysis vintage, HLA mismatch, peak PRA, total ischemic time and graft number. Cox proportional hazards ratios (HRs) are calculated using the $\operatorname{coxph}()$ function from the survival library. Data were analysed using a competing risk model using the mutually exclusive outcomes of Death before Recurrence (DbR), Graft Failure before Recurrence (GFbR) and Recurrence utilising the $\operatorname{Surv}()$ function with type="mstate".

\section{Results}

\section{Baseline demographics}

Sixteen thousand twenty-three renal transplants were performed between 1985 and 2013 of which 7,236 (45 · 16\%) were for biopsy-proven primary glomerulonephritis (GN). Characteristics of the patients are summarised in Table 1. The most common primary GN was IgA Nephropathy (IGAN) (33\%) followed by Focal Segmental Glomerulosclerosis (FSGS) (13.4\%). Amongst patients with primary GN (IGAN, FSGS, Membranous Nephropathy (MN) and Mesangiocapillary (MCGN) only) 2, $693(66.9 \%)$ transplants were from deceased donors, $892(22 \cdot 2 \%)$ from living related donors and $440(10.9 \%)$ were recipients from living unrelated donors.

\section{Increased glomerulonephritis recurrence in allografts from living related donors}

GN recurrence occurred in $424(10 \cdot 5 \%)$ of all primary GN allografts. GN recurrence rates were significantly higher in living related donor grafts compared to either living unrelated or deceased donor grafts $(p<0.001)$ (Fig. 1). At 10 years, $16 \cdot 2 \%$ of living related grafts had recurrent GN compared to $10 \cdot 3 \%$ of living unrelated and $8.9 \%$ of deceased donor grafts. There was significantly increased risks of GN recurrence with living related donor kidneys compared with deceased donor kidneys (HR:1 $7,95 \%$ CI:1 $4-2 \cdot 1, p<0 \cdot 00001$ ) or living unrelated donor kidneys (HR: $1 \cdot 6,95 \%$ CI:1 $05-2$. $4, p=0 \cdot 03)$. A competing risk model was used to compare rates of recurrence in deceased and related donor allografts. Ten year recurrence rates were slightly reduced at $7.5 \%$ for deceased and $14.8 \%$ for related donors but they remained statistically significant. These are compared with standard survival analysis results in Table 2.

IGAN and FSGS demonstrated increased rates of recurrence associated with living related donation. For IGAN, living related donor kidneys demonstrated a 10 year recurrence rate of $16 \cdot 7 \%$ (recurrence free survival $83 \cdot 3 \%$ (95\% CI 79.5-87.3)) compared to 7 . 1\% (recurrence free survival 92.9\% (95\% CI 87.9-98. 2)) for living unrelated donors and $9.2 \%$ (recurrence free survival $90 \cdot 8$ (95\% CI 89-92.7)) for deceased donors. In adjusted analysis, the risk of IGAN recurrence was significantly increased for living related donor kidneys compared to either deceased donor kidneys (HR:1 $\cdot 7,95 \%$ CI:1 $26-2 \cdot 26, p=0 \cdot 0005$ ) or living unrelated 
Table 1 Chracteristics of GN Patients by donor category

\begin{tabular}{|c|c|c|c|c|c|}
\hline & Deceased & Related & Unrelated & Total & $P$ value* \\
\hline GN Patients & 4956 & 1576 & 704 & 7236 & 0 \\
\hline Other Patients & 6201 & 1686 & 900 & 8787 & \\
\hline Total & 11157 & 3262 & 1604 & 16023 & \\
\hline \multicolumn{6}{|l|}{ GN patients } \\
\hline Age (Mean, SD) & $45.2(13.4)$ & $35.5(13.7)$ & $49.4(12)^{*}$ & $43.6(15.2)$ & $<0.0001$ \\
\hline \multicolumn{6}{|l|}{ GN Category } \\
\hline FSGS & $671(13.5)$ & $207(13.1)$ & $97(13.7)$ & $975(13.4)$ & \multirow[t]{5}{*}{$<0.0001$} \\
\hline $\lg A$ & $1552(31.3)$ & $557(35.3)$ & $284(40.3)$ & $2393(33)$ & \\
\hline MCGN & $260(5.2)$ & $57(3.6)$ & $31(4.4)$ & $348(4.8)$ & \\
\hline MN & $210(4.2)$ & $71(4.5)$ & $28(3.9)$ & $309(4.2)$ & \\
\hline Other GN & $2263(45.6)$ & $684(43.4)$ & $264(37.5)$ & $3211(44.3)$ & \\
\hline Male Gender, n (\%) & $3311(66.8)$ & $994(63)$ & $487(69.1)$ & $4792(66.2)$ & $<0.005$ \\
\hline Caucasian ethnicity, n (\%) & $4003(80.7)$ & $1283(81.4)$ & $586(83.2)$ & $5872(81.1)$ & 0.0006 \\
\hline \multicolumn{6}{|l|}{ Graft Number, n (\%) } \\
\hline Primary & $4385(88.4)$ & $1464(92.8)$ & $626(88.9)$ & $6475(89.4)$ & \multirow[t]{3}{*}{$<0.0001$} \\
\hline Secondary & $514(10.3)$ & $100(6.3)$ & $72(10.2)$ & $686(9.4)$ & \\
\hline Subsequent & $57(1.1)$ & $12(0.7)$ & $6(0.8)$ & $75(1)$ & \\
\hline Diabetes, n (\%) & $485(9.7)$ & $62(3.9)$ & $45(6.3)$ & $592(8.1)$ & $<0.0001$ \\
\hline Peak panel reactive antibodies (\%), Median (IQR) & $5(0-26)$ & $1(0-10)$ & $0(0-8)$ & $3(0-20)$ & $<0.001$ \\
\hline Total ischaemic time (hrs), Median (IQR) & $14(11-18)$ & $2(1-3)$ & $2(1-4)$ & $11(3-16)$ & $<0.001$ \\
\hline Zero HLA mismatches, n(\%) & $219(4.4)$ & $280(17.7)$ & $35(4.9)$ & $534(7.4 \%)$ & $<0.0001$ \\
\hline
\end{tabular}

${ }^{*} p$ values calculated with Student's $t$ test for continuous variables and Chi squared test for categorical variables

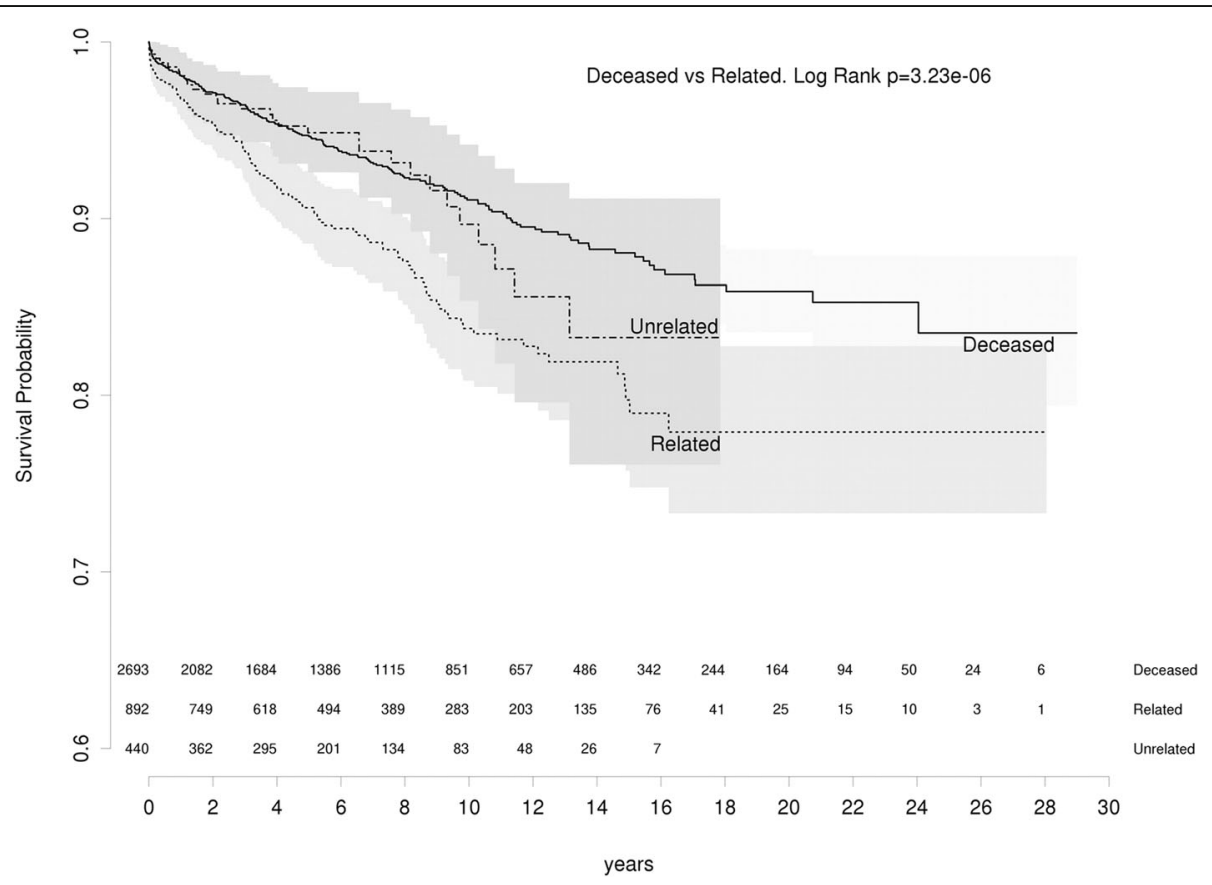

Fig. 1 All GNs: recurrence free survival living related vs living unrelated vs deceased 
Table 2 Recurrence rates by standard survival analysis and competing risk analysis. Mutually exclusive risks of Death before Recurrence, Graft Failure before Recurrence and Recurrence were used to construct the competing risk analysis

\begin{tabular}{llllll}
\hline \multirow{2}{*}{ Time (years) } & \multicolumn{2}{l}{ Competing risk analysis } & & \multicolumn{2}{l}{ Standard survival analysis } \\
\cline { 2 - 3 } & Deceased & Related & & Deceased & Related \\
\hline 5 & 4.8 & 9 & & 5.3 & 9.4 \\
10 & 7.5 & 14.8 & & 8.9 & 16.2 \\
15 & 9.3 & 17.7 & & 11.9 & 20.3 \\
20 & 10.2 & 18.8 & & 14.1 & 22.1 \\
\hline
\end{tabular}

donor kidneys (HR:2.2, 95\% CI:1.2-4.0, $\quad p=0 \cdot 009)$ (Fig. 2).

In FSGS, living related grafts had an elevated risk of recurrence at 10 years of $14.6 \%$ (recurrence free survival $85 \cdot 4 \%$, 95\% CI $79 \cdot 6-91 \cdot 6$ ) compared to $10 \cdot 8 \%$ among living unrelated donors (recurrence free survival $89.2 \%$, $95 \%$ CI $80 \cdot 6-98 \cdot 7)$ and $6 \cdot 6 \%$ in deceased donors (recurrence free survival 93.4\% 95\% CI 91·2-95.6). However, on adjusted analysis, the risk of FSGS recurrence in living related donor kidneys was significantly increased compared only with deceased donor kidneys (HR:2 2 , 95\% CI 1 34-3 - 64, $p=0 \cdot 002$ ) and not with living unrelated donor kidneys (HR:1 4 , 95\% CI 0 - 63-3 • 1 , $p=0 \cdot 4)$. There was no difference in the rates of recurrence free survival based on donor category among patients with $\mathrm{MN}(p=0 \cdot 2)$ or MCGN ( $p=0 \cdot 6)$ (Fig. 2).

Increased glomerulonephritis recurrence in living related kidney transplants does not impair graft survival

We hypothesised that increased GN recurrence would have a negative effect on allograft survival and increased GN recurrence may mitigate the benefits of live donation. However, for all primary glomerulonephritides death censored graft survival (DCGS) was superior for live donor grafts compared to graft survival in deceased donor grafts $(P<0 \cdot 001)$ and this survival advantage was maintained in living related donor grafts (Fig. 3).

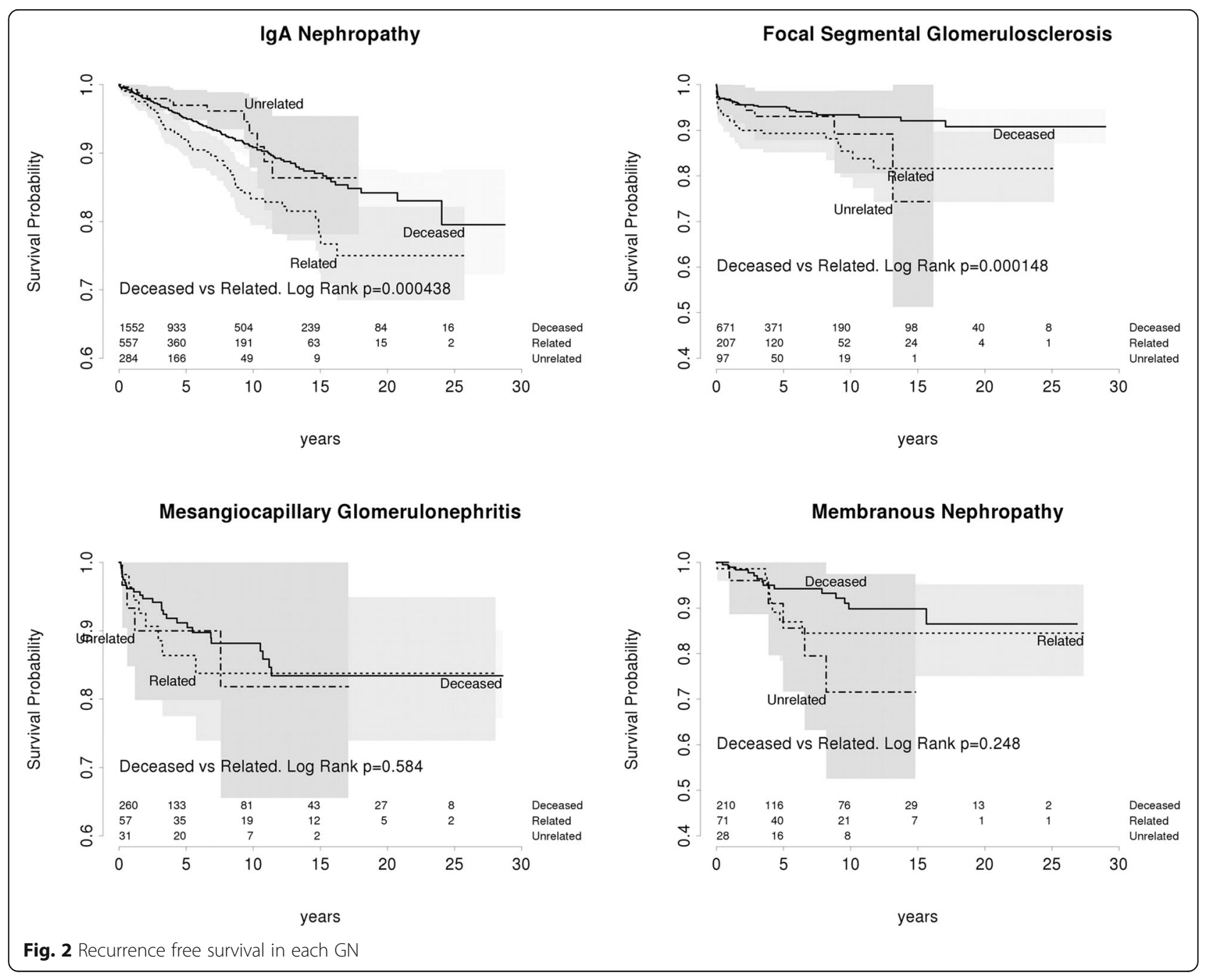


Death censored graft survival in all GN

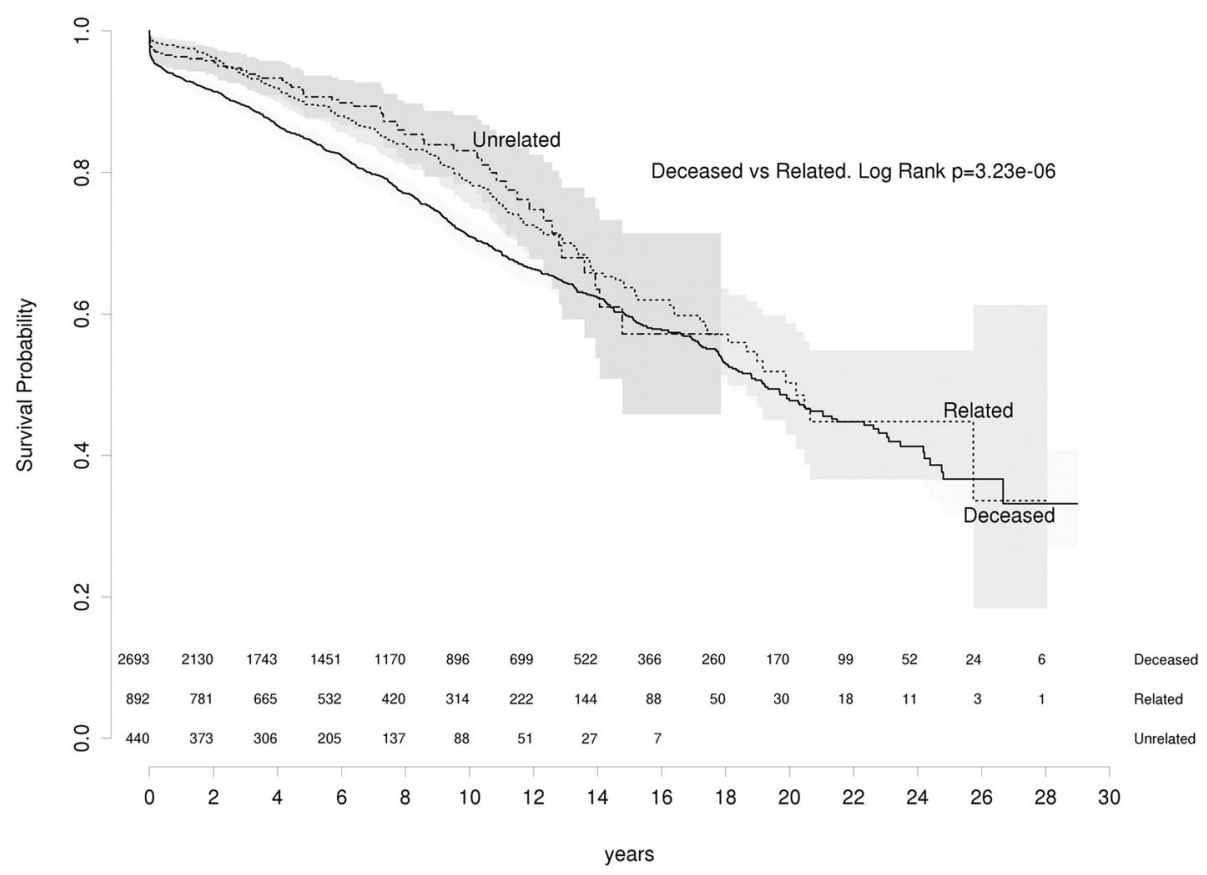

Fig. 3 All GN: Death censored graft survival living related vs living unrelated vs deceased

In IGAN, living donor grafts had superior DCGS compared to deceased donor grafts $(p=0.002)$ (Fig. 4). In contrast, there was no significant difference in $\mathrm{MN}$, FSGS or MCGN (Fig. 4). In FSGS at 5 and 10 years, DCGS showed a non-significant trend towards improvement for any live donor kidney (Fig. 4).

We examined graft survival from time of recurrence (Fig. 5). There was no difference observed in graft survival of patients with recurrence of GN based on donor status. At 5 years, DCGS was $41 \cdot 6 \%(95 \%$ CI $35 \cdot 2-49$. 1 ) in deceased donor grafts and $52 \cdot 9 \%$ (CI $44 \cdot 8-62 \cdot 4$ ) in living related grafts. Therefore there is no evidence that living related grafts have more aggressive recurrent disease than deceased donor grafts.

\section{HLA mismatch does not associate with increased risk of glomerulonephritis recurrence}

We tested whether increased recurrence in IGAN and FSGS related to shared HLA antigens. The risk of recurrence was not significantly increased by in zeromismatched grafts (Fig. 6). This suggests that the increased risk of recurrence associated with living related donation is not due to shared HLA but other heritable kidney-intrinsic factors.

\section{Discussion}

Our study demonstrates an increased risk of primary GN recurrence within renal allografts from living related donors, mainly in patients with IGAN and FSGS. Increased risk with live donation has been reported in a number of studies of primary GN, and specifically in IGAN [16-21], FSGS [22-24] and MCGN [25-28]. This is the largest study of primary GN recurrence in transplantation on the effect of living related donation.

Current studies of the effect of donor status on recurrence and outcome are unclear. A meta-analysis of the effect of donor status reported a higher risk of IgA recurrence in living related grafts but a non-significant trend in the risk of graft loss [29]. The ERA-EDTA registry analysis [26] reported increased MCGN recurrence, but equivalent graft survival in living donor grafts, whether related or not. Other studies have likewise failed to find an association between live related donation and GN recurrence [30-33].

The mechanism of increased GN recurrence risk in living related grafts is unclear. This study implicates genetic risks for IGAN and FSGS manifesting in a kidney-intrinsic manner. However, it remains unclear if recurrence of IGAN is [34, 35] or is not [32, 36] more frequent in transplants with zero HLA mismatches. In this study we did not identify an elevated risk due to HLA, suggesting an alternative genetic mechanism. This study cannot exclude a role for minor HLA antigens.

Despite the elevated risk of GN recurrence demonstrated in grafts from living related donors, deathcensored graft survival was still superior for patients 


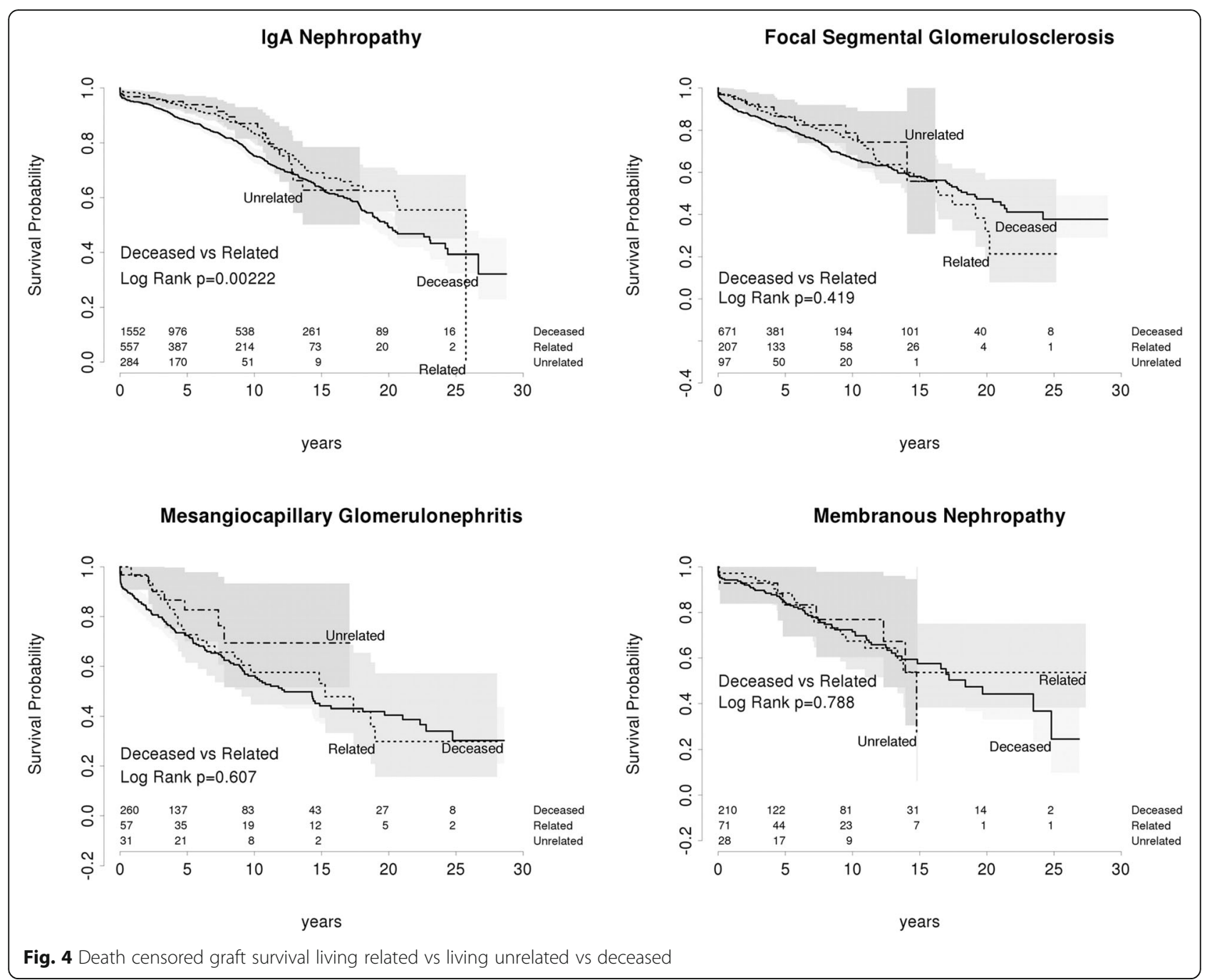

with IGAN compared to deceased donors, and no difference was observed in death-censored graft survival in MN, FSGS or MCGN. Our study shows that, for those with a primary diagnosis of IGAN or FSGS, the benefit of live allograft donation is maintained regardless of the elevated risk of GN recurrence. This benefit does not appear to be present for patients with membranous or MCGN. Therefore, increased recurrence rates do not outweigh the superior outcomes associated with living donation, in agreement with previous studies [5, 7, 19, 26]. Based on our observations, live donor allografts remain the standard for transplantation in primary GN.

Whilst this is a large, well-characterised study population with 28 years follow-up, we acknowledge the limitations inherent in registry analysis. Despite these limitations, this study represents the most complete and well-populated registry analysis to date.

The increasing use of protocol biopsies post transplantation has the potential to alter the results of this analysis. The significance of histological evidence of recurrence in the absence of clinical evidence of glomerulonephritis is unclear. It may be argued that to adequately document the incidence and prevalence of post-transplant GN, a protocol biopsy regimen should be mandatory. Under those circumstances, it is highly likely that the GN recurrence rate would rise, but the overall impact on graft survival may fall. Whilst this might increase scientific rigour, it remains to be shown that such a policy can improve outcomes, both for recurrent $\mathrm{GN}$ and graft survival.

\section{Conclusions}

In this Registry analysis of 7,236 patients with primary glomerulonephritis who received renal allografts between 1985 and 2013 we identified a significant increase in the risk of GN recurrence in patients suffering from IGAN and FSGS where donation occurs from a living related donor compared to a deceased donor. Despite this elevated risk of recurrent disease, the survival advantage of living related donation is maintained. We 


\section{Death censored graft survival in GN patients with recurrence}

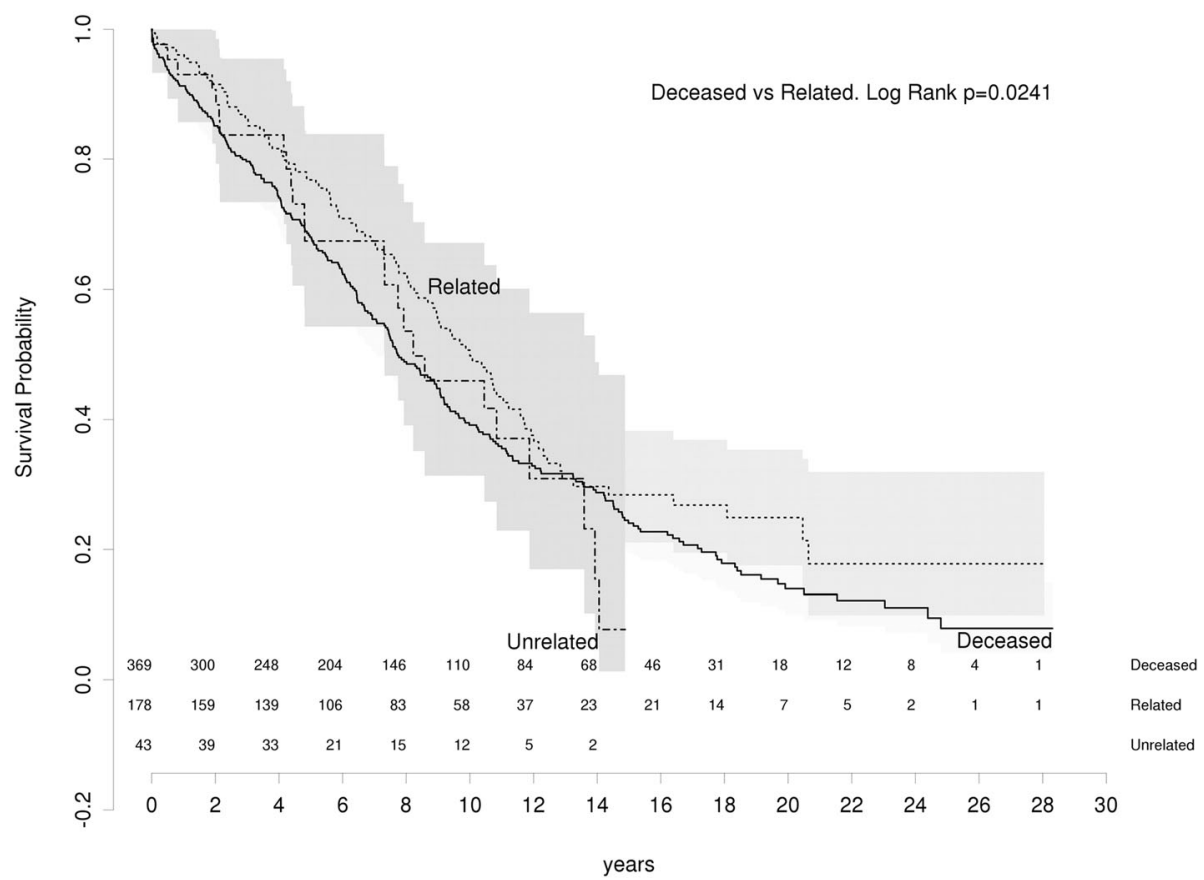

Fig. 5 Death censored graft survival in grafts with recurrent disease living related vs unrelated from time of recurrence

Recurrence free survival in GN patients by HLA mismatches

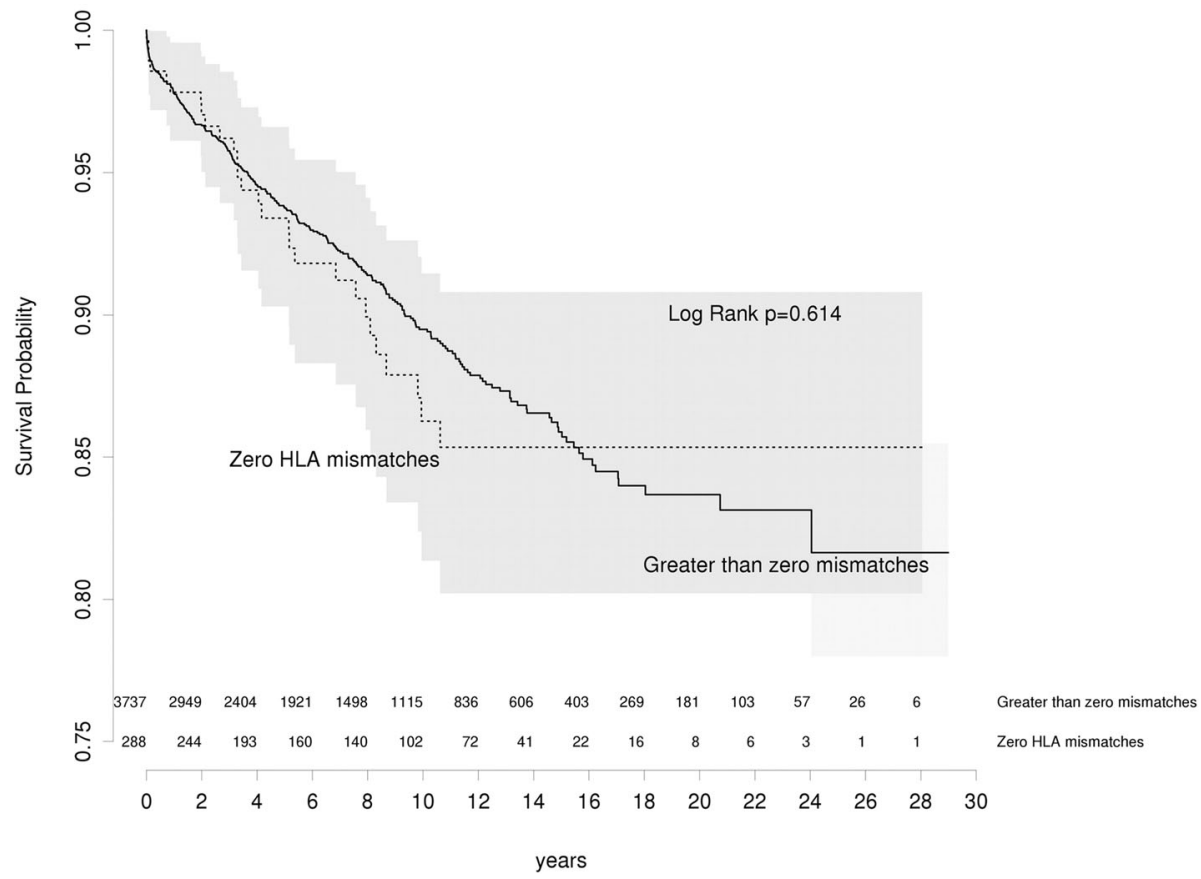

Fig. 6 Recurrence free survival by HLA matching in living related or living unrelated grafts 
conclude that there is no reason to avoid living related donation in recipients with primary GN despite the elevated risks. Potential recipients should, however, be informed of the increased risk of disease recurrence when receiving an organ from a relative.

\section{Abbreviations}

Cl: Confidence interval; DCGS: Death censored graft survival; FSGS: Focal and segmental glomerulosclerosis; GN: Glomerulonephritis; HR: Hazard ratio; IGAN: IgA nephropathy; MCGN: Mesangiocapillary glomerulonephritis; MN: Membranous nephropathy

\section{Acknowledgements}

The data reported here have been supplied by the Australia and New Zealand Dialysis and Transplant Registry (ANZDATA). The interpretation and reporting of these data are the responsibility of the authors and in no way should be seen as an official policy or interpretation of the Australia and New Zealand Dialysis and Transplant Registry. SJ has been supported by an NHMRC Jacquot Award for Excellence and the RACP Foundation.

\section{Funding}

Not applicable.

\section{Availability of data and materials}

The datasets generated for this study are available in the LabArchives repository at doi: 10.6070/H4Z60M30.

\section{Authors' contributions}

AK contributed data acquisition, data analysis and interpretation, drafting and revision of the manuscript. SJ contributed study conception, data analysis and interpretation, drafting and revision of the manuscript. GW contributed study conception, data acquisition, data analysis and interpretation, drafting and revision of the manuscript. All authors have approved the final manuscript and take full responsibility for its content and accuracy.

\section{Competing interests}

The authors declare that they have no competing interests.

\section{Consent for publication}

The manuscript contains no indentifiable or re-identifiable data, therefore no consent to publish was sought.

\section{Ethics approval and consent to participate}

No specific ethics approval has been sought for this study. Data was sought under standard processes for the ANZDATA registry. All patients consent to have their data collected and analysed prior to data entry in the Registry.

\section{Author details}

${ }^{1}$ Department of Renal Medicine, The Canberra Hospital, PO Box 11, Woden, ACT 2605, Australia. '2Department of Immunology and Infectious Diseases, John Curtin School of Medical Research, Australian National University, Canberra, Australia. ${ }^{3}$ Australian National University Medical School, Garran, Australia. ${ }^{4}$ ANZDATA Registry, Adelaide 5000, Australia.

Received: 27 October 2016 Accepted: 28 December 2016 Published online: 17 January 2017

\section{References}

1. Rabbat CG, Thorpe KE, Russell ID, Churchill DN. Comparison of mortality risk for dialysis patients and cadaveric first renal transplant recipients in Ontario, Canada. J Am Soc Nephrol. 2000;11:917-22.

2. Terasaki PI, Cecka JM, Gjertson DW, Takemoto S. High survival rates of kidney transplants from spousal and living unrelated donors. N Engl J Med. 1995;333:333-6.

3. Briganti EM, Russ GR, MCNeil JJ, Atkins RC, Chadban SJ. Risk of renal allograft loss from recurrent glomerulonephritis. N Engl J Med. 2002;347:103-9.

4. Hariharan S, Adams MB, Brennan DC, Davis CL, First MR, Johnson CP, et al. Recurrent and de novo glomerular disease after renal transplantation: a report from Renal Allograft Disease Registry (RADR) 1, 2. Transplantation. 1999;68:635-41.
5. Moroni G, Longhi S, Quaglini S, Rognoni C, Simonini P, Binda V, et al. The impact of recurrence of primary glomerulonephritis on renal allograft outcome. Clin Transplant. 2014;28:368-76.

6. Floege J. Recurrent glomerulonephritis following renal transplantation: an update. Nephrol Dial Transplant. 2003;18:1260-5.

7. Ponticelli C, Glassock RJ. Post-transplant recurrence of primary glomerulonephritis. Clin J Am Soc Nephrol. 2010;5:2363-72.

8. Golgert WA, Appel GB, Hariharan S. Recurrent glomerulonephritis after renal transplantation: an unsolved problem. Clin J Am Soc Nephrol. 2008;3:800-7.

9. Kiryluk K, Li Y, Scolari F, Sanna-Cherchi S, Choi M, Verbitsky M, et al. Discovery of new risk loci for IgA nephropathy implicates genes involved in immunity against intestinal pathogens. Nat Genet. 2014;46:1187-96.

10. Kopp JB, Smith MW, Nelson GW, Johnson RC, Freedman BI, Bowden DW, et al. $\mathrm{MYH} 9$ is a major-effect risk gene for focal segmental glomerulosclerosis. Nat Genet. 2008;40:1175-84.

11. Fronek Z, Timmerman LA, Alper CA, Hahn BH, Kalunian K, Peterlin BM, et al. Major histocompatibility complex genes and susceptibility to systemic lupus erythematosus. Arthritis Rheum. 1990;33:1542-53.

12. Salmon JE, Millard S, Schachter LA, Arnett FC, Ginzler EM, Gourley MF, et al. Fc gamma RIIA alleles are heritable risk factors for lupus nephritis in African Americans. J Clin Invest. 1996;97:1348-54.

13. R: The R Project for Statistical Computing. [cited 7 Apr 2016]; Available from: https://www.r-project.org/

14. Therneau TM, Thomas Lumley (original S.- $>$ R port and maintainer until 2009). survival: Survival Analysis. 2015 Jul 2 [cited 7 Apr 2016]; Available from: https://cran.r-project.org/web/packages/survival/index.html

15. Jr FEH. rms: Regression Modeling Strategies. 2016 Apr 4 [cited 7 Apr 2016]; Available from: https://cran.r-project.org/web/packages/rms/index.html

16. Freese $P$, Svalander $C$, Nordén G, Nyberg G. Clinical risk factors for recurrence of IgA nephropathy. Clin Transplant. 1999;13:313-7.

17. Andresdottir MB, Hoitsma AJ, Assmann KJ, Wetzels JF. Favorable outcome of renal transplantation in patients with IgA nephropathy. Clin Nephrol. 2001;56:279-88.

18. Bachman U, Biava C, Amend W, Feduska N, Melzer J, Salvatierra O, et al. The clincial course of IgA Nephropathy and Henoch-Schonlein Purpura following renal transplantation. Transplantation. 1986;42:511-4.

19. Han SS, Sun H-K, Lee JP, Ha JW, Kim SJ, Kim YS. Outcome of renal allograft in patients with Henoch-Schönlein nephritis: single-center experience and systematic review. Transplantation. 2010;89:721-6.

20. Wang AYM, Lai FM, Yu AW-Y, Lam PKW, Chow KM, Choi PCL, et al. Recurrent IgA nephropathy in renal transplant allografts. Am J Kidney Dis. 2001;38:588-96.

21. Bumgardner GL, Amend WC, Ascher NL, Vincenti FG. Single-center longterm results of renal transplantation for IgA Nephropathy. Transplantation. 1998;65:1053-60.

22. Baum MA, Stablein DM, Panzarino VM, Tejani A, Harmon WE, Alexander SR. Loss of living donor renal allograft survival advantage in children with focal segmental glomerulosclerosis. Kidney Int. 2001;59:328-33.

23. Abbott KC, Sawyers ES, Oliver JD, Ko CW, Kirk AD, Welch PG, et al. Graft loss due to recurrent focal segmental glomerulosclerosis in renal transplant recipients in the United States. Am J Kidney Dis. 2001;37:366-73.

24. Baum MA. Outcomes after renal transplantation for FSGS in children. Pediatr Transplant. 2004:8:329-33.

25. Green H, Rahamimov R, Rozen-Zvi B, Pertzov B, Tobar A, Lichtenberg S, et al. Recurrent Membranoproliferative Glomerulonephritis Type I after kidney transplantation: a 17-year single-center experience. Transplantation. 2015;99:1172-7.

26. Pippias M, Stel VS, Aresté-Fosalba N, Couchoud C, Fernandez-Fresnedo G, Finne $P$, et al. Long-term kidney transplant outcomes in primary Glomerulonephritis: analysis from the ERA-EDTA registry. Transplantation. 2016; 100(9):1955-62.

27. Andresdottir MB, Assmann KJ, Hoitsma AJ, Koene RA, Wetzels JF. Recurrence of type I membranoproliferative glomerulonephritis after renal transplantation: analysis of the incidence, risk factors, and impact on graft survival. Transplantation. 1997;63:1628-33.

28. Lorenz EC, Sethi S, Leung N, Dispenzieri A, Fervenza FC, Cosio FG. Recurrent membranoproliferative glomerulonephritis after kidney transplantation. Kidney Int. 2010;77:721-8.

29. Choy BY, Chan TM, Lai KN. Recurrent glomerulonephritis after kidney transplantation. Am J Transplant. 2006;6:2535-42.

30. Ponticelli C, Traversi L, Feliciani A, Cesana BM, Banfi G, Tarantino A. Kidney transplantation in patients with IgA mesangial glomerulonephritis. Kidney Int. 2001;60:1948-54 
31. Moriyama T, Nitta K, Suzuki K, Honda K, Horita S, Uchida K, et al. Latent IgA deposition from donor kidney is the major risk factor for recurrent IgA nephropathy in renal transplantation. Clin Transplant. 2005;19:41-8.

32. Frohnert PP, Donadio Jr JV, Velosa JA, Holley KE, Sterioff S. The fate of renal transplants in patients with IgA nephropathy. Clin Transplant. 1997;11:127-33.

33. Kim YS, Moon Jl, Jeong HJ, Kim MS, Kim SI, Choi KH, et al. Live donor renal allograft in end-stage renal failure patients from immunoglobulin a nephropathy1, 2. Transplantation. 2001;71:233-8.

34. Andresdottir MB, Hoitsma AJ, Assmann KJM, Koene RAP, Wetzels JFM. The impact of recurrent glomerulonephritis on graft survival in recipients of human histocompatibility leucocyte antigen-identical living related donor grafts. Transplantation. 1999;68:623-7.

35. McDonald SP, Russ GR. Recurrence of IgA nephropathy among rena allograft recipients from living donors is greater among those with zero HLA mismatches. Transplantation. 2006:82:759-62.

36. Choy BY, Chan TM, Lo SK, Lo WK, Lai KN. Renal transplantation in patients with primary immunoglobulin A nephropathy. Nephrol Dial Transplant. 2003;18:2399-404.

Submit your next manuscript to BioMed Central and we will help you at every step:

- We accept pre-submission inquiries

- Our selector tool helps you to find the most relevant journal

- We provide round the clock customer support

- Convenient online submission

- Thorough peer review

- Inclusion in PubMed and all major indexing services

- Maximum visibility for your research

Submit your manuscript at www.biomedcentral.com/submit
Biomed Central 